\title{
ПОВЕДЕНИЕ/РАЗМНОЖЕНИЕ/ЖИЗНЕННЫЙ ЦИКЛ КРИЛЯ КАК МАРКЕР КЛИМАТИЧЕСКИХ ИЗМЕНЕНИЙ В АНТАРКТИКЕ (ОБЗОР ЛИТЕРАТУРЫ)
}

\section{BEHAVIOR/REPRODUCTION/LIFE CYCLE OF KRILL AS A MARKER OF CLIMATE CHANGE IN THE ANTARCTIC}

I. Blagodurov

Summary. In recent years, the polar regions have received increasing scientific and public attention. interest. Both the Arctic and Antarctic are recognized as key regions in the regulation of the global climate and polar ecosystems are particularly susceptible to ongoing environmental changes. Ecology aims to advance scientific knowledge about the polar and subpolar regions of both hemispheres by facilitating the rapid and widespread dissemination of new scientific information from recent marine research, freshwater and terrestrial biota to polar researchers, environmental managers and policymakers. Krill is a high-latitude species of Antarctic macroplankton. The transfer of crustaceans to the north occurs with the western branches of the cyclones. How far it will go depends on the development of these circulation branches. The northern boundary of the massive krill drift is the Antarctic Secondary Frontal Zone. Removal from it can be considered sterile or non-sterile eviction. Some krill penetrate the shelves of some of the seas, thanks to currents associated with underwater troughs that cut the slope and shelf. Warm deep waters that penetrate into the shelf zone play an important role in this process. Consequently, it is necessary to significantly intensify international efforts in the field of polar research, and interaction between the scientific community of researchers at the North and South Poles.

Keywords: euphausia superba, antarctic krill, fisheries, marine resources, Antarctica, oceans, climate changes.

\section{Ввеление}

Б олее полувека назад Джеймс Марр опубликовал свою знаменитую работу «История и география обитания антарктического криля (Euphausia superba)» (Marr, 1962). С самого начала антарктического китобойного промысла китобои знали, что E. superba является основным продуктом питания для усатых китов. Таким образом, они искали красноватого цвета воды, которые указали на огромные стаи криля в те дни. Написание научной работы относительно происхождения и географии миграции арктического криля начиналось именно по следам китобоев. В течение полувека иссле-
Благодуров Илья Сергеевич

Аспирант, ФГБОУ ВО «Калининградский государственный технический университет» ilya.blagodurov@klgtu.ru

Аннотация. В последние годы полярные регионы получили все большее научное и общественное внимание. И Арктика, и Антарктика признаны ключевыми регионами регулирования глобального климата и полярных экосистем, которые особенно восприимчивы к продолжающимся изменениям окружающей среды. Экология призвана способствовать прогрессу научных знаний о полярных и субполярных регионах обоих полушарий, способствуя быстрому и широкому распространению новой научной информации, полученной в результате недавних исследований моря, ее биоты. Криль относится к высокоширотным видам антарктического макропланктона. Вынос рачков на север происходит с западными ветвями циклонов. Насколько далеко его уносит, зависит от развития этих ветвей циркуляции. Северной границей массового дрейфа криля служит Вторичная фронтальная зона Антарктики. Выносы за её пределы считают стерильным или нестерильным выселением. Часть криля проникает на шельфы некоторых из морей, благодаря течениям, связанным с подводными ложбинами, секущими склон и шельф. Большую роль в этом процессе играют тёплые глубинные воды, проникающие в шельфовую зону. Следовательно, необходимо значительно активизировать международные усилия в области полярных исследований, и взаимодействие между научным сообществом исследователей Северного и Южного полюсOB.

Ключевые слова: euphausia superba, антарктический криль, рыбный промысел, морские ресурсы, Антарктика, Мировой океан, изменения климата.

дования оставались мотивированными важностью китов и китобойного промысла. Экспедиции Discovery финансировалась за счет сборов с китобойного промысла и проводилась в районе острова Южная Джорджия и других британских островов в том регионе.

Трактат Джеймса Марра представляет собой в основном компиляцию результатов исследований в течение трех десятилетий XX века. Следует отметить, что исследования арктического криля не умерли вместе с китобойным промыслом. После истощения в Антарктике запасов китов, новый интерес к крилю возник в 1970-х годах. 
В то время отчет Римского клуба привлек внимание общественности к морю как к источнику белка для питания постоянно растущего населения Земли. Одновременно, новый морской закон убрал иностранные рыболовные флотилии из исключительных экономических зон (ИЭЗ). Эти флоты искали новые места для лова рыбы и новые виды рыбы, пригодные для рыбной ловли в промышленных масштабах. Южный океан был одним из тех немногих открытых регионов, где промысел криля стал ответом на глобальную нехватку белка. Экспериментальный промысел и обработка в море продемонстрировали возможность успешной эксплуатации данного вида океанской биоты. Кульминацией нового этапа исследований арктического криля стала международная программа BIOMASS, запущенная в 1980-е гг. XX века. Ученые из многих стран предоставили огромное количество информации по биологии E. superba, еe распространению, численности и колебаниям. Однако мечты о многомиллионной эксплуатации антарктического криля рассеялись по экономическим и техническим причинам. Кроме того, в ходе реализации BIOMASS были выявлены гораздо более низкие цифры численности криля, чем предполагалось ранее. Наконец, новое мышление с точки зрения сохранения морской экосистемы Антарктики потребовало предупредительное управление эксплуатацией криля.

В конце этого второго этапа исследования криля и четыре десятилетия спустя после величайшей работы Джеймса Марра, Иниго Эверсон представил исчерпывающий обзор знаний об $E$. superba и родственных видов эвфаузиид (Everson, 2000). К концу двадцатого века общественный интерес к антарктическому крилю значительно снизился. Но в начале текущего столетия интерес к теме криля проснулся с удвоенной силой, поскольку современные экологи все больше осознают изменения ледяного покрова и их влияние на пополнение и распределение криля. Учитывая центральную роль криля в сложной морской экосистеме, исследования арктического криля опять привлекли международное внимание. Масштабные исследования указали на существенное общее снижение биомассы криля в различных частях Южного океана за последние три десятилетия, особенно в районе Антарктического полуострова. До сих пор рыбный промысел был намного ниже устойчивого допустимого уровня эксплуатации. Но экономический интерес к арктическому крилю как источнику ценных биохимических материалов опять растет. Таким образом, понимание масштабов и механизмов межгодовых и сезонных изменений ледовых условий Южного океана и их влияние на численность арктического криля представляется одной из важнейших задач, решение которых необходимо для создания научной основы возобновления его промысла.

\section{Шель работы}

Выявление особенностей численности и миграции антарктического криля с потоками течений в Атлантическом секторе Антарктики как показатель климатических изменений.

Для осуществления поставленной цели, в рамках данной работы решались следующие задачи:

1. Исследовать распределение антарктического криля в Атлантическом секторе Антарктики;

2. Выявить особенности сезонной динамики численности антарктического криля и распределения промысловых скоплений в подрайонах Атлантического сектора Антарктики.

\section{Материалы и метолы}

Было проанализировано порядка 20 отечественных и зарубежных источников литературы по выбранной тематике.

\section{Результаты}

Жизненный цикл E. superba изучают давно и вкратце его можно представить себе следующим образом. Особи E. superba живут в среднем 2,5-3 года. В первое лето рачки проходят личиночное развитие, во второе они существуют в виде молоди, а в третье - созревают и, приступая к нересту в начале декабря, к марту, отнерестившись, постепенно отмирают. Однако при неблагоприятных условиях рачки могут существовать в виде молоди не одно лето, а два. Это может, например, наблюдаться у особей, появившихся на свет в самом конце периода нереста. Кроме того, есть основания считать, что в районе течения Восточных Ветров рачки живут четыре года, а в водах моря Уэдделла - три. Далее, есть мнение, что вообще все особи этого вида живут 4 года, однако это сомнительно. По мере роста и созревания рачков происходит круглогодичное закономерное изменение состава популяции E. superba.

В конце зимы-начале весны идет подготовка к нересту, в популяции мало личинок. В течение лета наблюдается постепенное изменение соотношения возрастных групп, обусловленное появлением на свет множества личинок и естественным отмиранием отнерестившихся рачков. Зимой молодь достигает половой зрелости, а личинки превращаются в молодь. В годы с разными гидрометеорологическими условиями наступление одинаковых фаз жизненного цикла происходит в разные календарные сроки. В результате этого сроки появления рачков в районе нереста, их рассредоточение после завершения икрометания, сроки доминирования соответствующих возрастных групп в популяции 


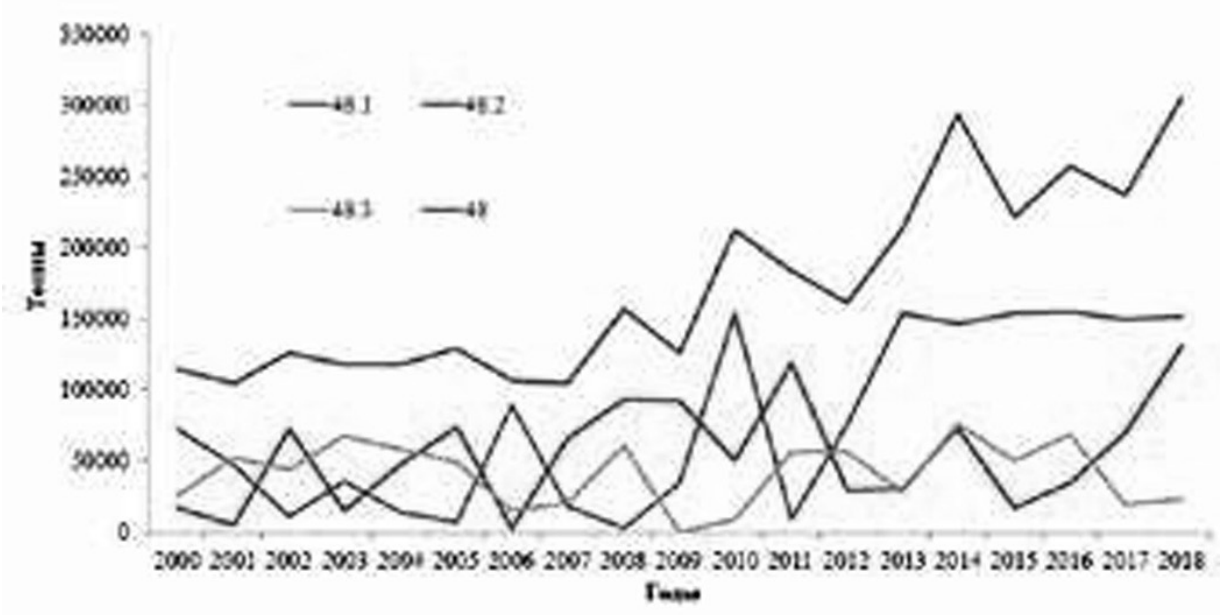

Рис. 1. Уловы антарктического криля по подрайонам в АчА за период 2000-2018 гг. [6]

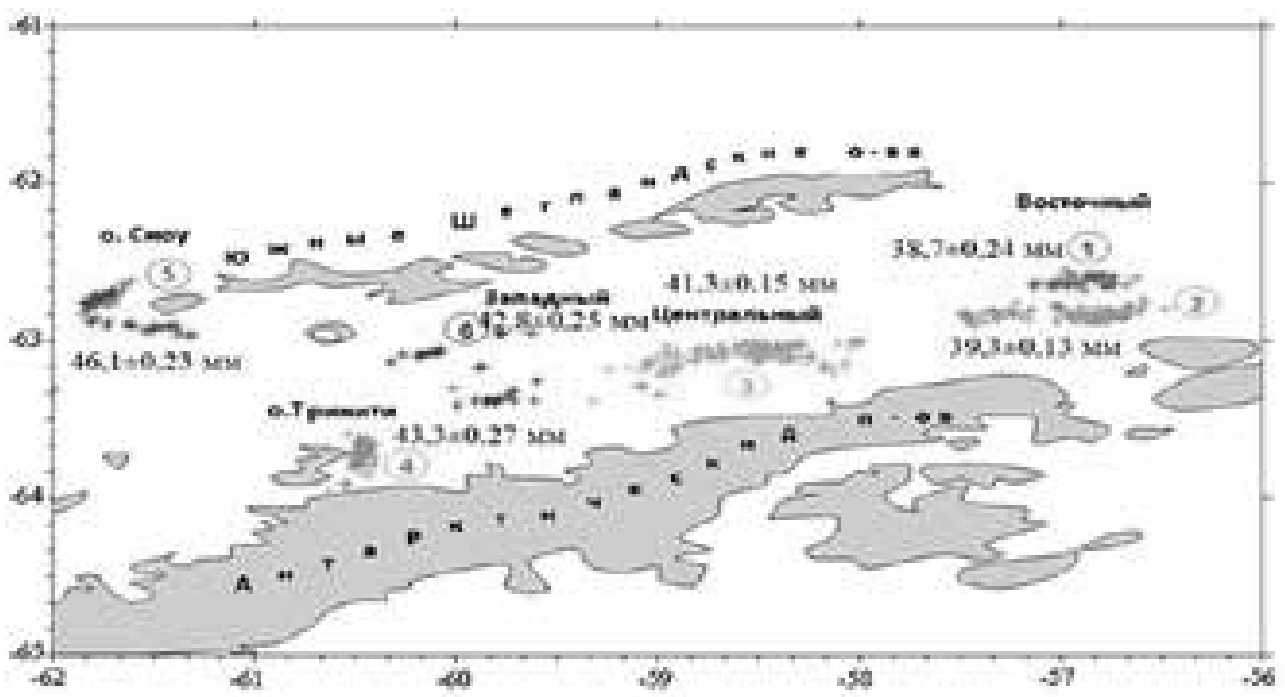

Рис. 2. Схема промысловых участков и средняя длина криля в проливе Брансфилд в феврале-июне 2017 года

и т.д. могут оказаться сдвинутыми по времени от года к году.

Таким образом, E. superba имеет трехгодичный жизненный цикл, и в популяции присутствуют три размерно-возрастные группы особей: личинки, молодь и половозрелые рачки.

Как было сказано выше, наложение квот на вылов криля привел к снижению его добычи в водах Южного океана.

Антарктическая комиссия по сохранению морских живых ресурсов Антарктики (АНТКОМ) ввела ограни- чение на ежегодный вылов рачков в АЧА на уровне 620 тыс. т, не столько с целью рационального природопользования ресурса криля, а защитой животных, питающихся крилем от предполагаемого, но научно не доказанного конкурентного влияния крилевого промысла. Введение ограничения на вылов привело к тому, что в подрайоне 48.1 (Антарктический полуостров) промысел криля в последние 5 лет прекращался из-за выбора квоты 155 тыс. т (рис. 1) составляющей 3\% от биомассы в АЧА (5,61 млн. т).

На рисунке 2 представлена схема промысловых участков и средняя длина криля в проливе Брансфилд в феврале-июне 2017 года 
По данным ряда ученых (Hill, S.L., A. Atkinson, C. Darby, et al. 2016), плотность криля на шести участках колебалась от 1,4 до 102,0 г/м3. Средневзвешен-

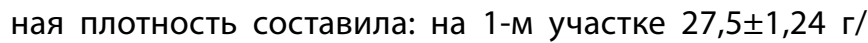

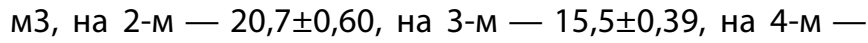

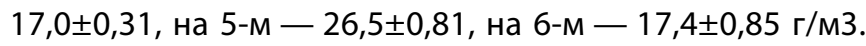
На всей обследованной акватории пролива Брансфилд она равнялась $18,4 \pm 0,34$ г/м3

Распределение вылавливаемых рачков и частота их встречаемости во многом определяются сезонным развитием популяции и общим ходом жизненного цикла рачка.

Другим фактором, влияющим на количественное распределение рачков, является перемещение их по акватории в пределах ареала. Euphausia superba имеет циркумантарктический ареал и обитает в основном в водах течения Восточных Ветрову водах моря Уэдделла.

Севернее, в пределах Антарктического циркумполярного течения (течения Западных Ветров), рачки встречаются значительно реже и далеко не везде. Появлению их там способствует локальные изменения направления течения Восточных Ветров к северу и северо-востоку. Эти изменения обусловлены особенностями рельефа [4].

Постоянный круговорот, имеющий, несомненно, большое значение для поддержания популяции $E$. superba, находится в северо-восточной части моря Уэдделла. Такие круговороты, может быть более мелкого масштаба, встречаются и в других районах Южного океана, например, в районе моря Росса или о. Кергелен [6].

Согласно представлениям К.В.Беклемишева, ареал пелагических животных может быть подразделен на несколько соподчиненных зон, связанных с основой ареала, которая располагается в районе постоянной циркуляции вод, где имеются условия, обеспечивающие сохранение переживающего фонда популяции. Отсюда происходит постоянный вынос, но эта убыль компенсируется размножением особей основного фонда популяции. Кроме того, в процессе переноса с трансформированными водными массами, но еще мало отличающимися от первоначальных, размножение планктеров какое-то время может продолжаться.

В принципе такой должна быть структура ареала $E$. superba - типичного пелагического рака. Конечно, оценка отдельных частей ареала этого вида с точки зрения воспроизводства обитающих здесь рачков пока затруднена. Конкретные материалы имеются в настоящее время только для атлантического сектора, где исследования распределения E. superba проводятся с 1962 г.

Нерест половозрелых особей происходит в районе моря Скоша в пределах зоны смешения вод моря Уэдделла и Антарктического циркумполярного течения (течения Западных Ветров). Эта зона располагается вдоль южной части «дуги Скоша», отклоняясь в восточной части моря Скоша к северу [2].

По данным ряда авторов, район между Южными Шетландскими и Южными Сандвичевыми островами и особенно район Южных Оркнейских островов являются одним из мест размножения E. superba в Южном океане и, по-видимому, главным местом размножения рачков, обитающих в море Уэдделла. В дальнейшем часть личинок, благодаря вертикальным и горизонтальным миграциям, попадает в район основной циркуляции ареала, располагающейся в море Уэдделла, и возвращается к югу. Однако остальные личинки выносятся водами моря Уэдделла на восток [4].

Скопления личинок в виде «пятен», находящихся на старших стадиях фурцилия, были встречены в 1969 г. в центральных районах моря Скоша через несколько недель после завершения нереста. Они дрейфуют на восток. Считая основным центром размножения E. superba в этом районе воды моря Уэдделла, Марр полагает, что появление личинок в этих широтах (но далеко к востоку) происходит в результате пассивного сноса личинок течением. Однако он не исключает возможности того, что $E$. superba в небольшом количестве размножается и к востоку от моря Скоша, и, следовательно, «шлейф» личинок, тянущийся от моря Скоша до $30^{\circ}$ в.д., объясняется как выносом личинок из основных районов размножения, так и размножением местных популяций рачка [11].

Особей, появившихся на свет в данном году и совершивших благодаря круговому течению за осень и зиму циркуляцию в море Уэдделла, на следующее лето можно встретить в водах северной части моря Уэдделла в виде молоди. Рачки распределены, как правило, дисперсно и интенсивно питаются. Осенью и зимой (вторая зима в их жизни) часть молоди, так же как в прошлом году личинок, уносится на восток с водами моря Уэдделла, а другая часть их совершает, возможно, второй раз циркуляцию в море Уэдделла. Однако это перемещение происходит уже по несколько другому маршруту. В результате на следующее, третье, лето они в виде половозрелых особей оказываются севернее в районе зоны смешения вод моря Уэдделла и течения Западных Ветров. Это предполагаемое несовпадение путей дрейфа личинок и молоди обусловливает картину раздельного существования половозрелых особей (обитающих севернее) и молоди (обитающей южнее). 
После нереста рачки в основном погибают, а оставшиеся выносятся водами моря Уэдделла на восток. Не исключена также возможность, что часть их в третий раз попадает в круговое течение моря Уэдделла.

Таким образом, круговорот вод в море Уэдделла обеспечивает существование независимой популяции E. superba. В восточной части моря Скоша и в водах к востоку от Южных Сандвичевых островов находятся, по-видимому, зависимые или полузависимые популяции этого рачка, поскольку особи E. superba, видимо сохраняют здесь способность к размножению [11]. Еще восточнее рачки попадают в стерильную зону выселения с необычно высокими значениями температуры.

Характерным примером такой зоны является район о. Южная Джорджия, где размножение E. superba не происходит. В 1968 и в 1969 гг. XX века здесь наблюдался нерест рачков, но по-видимому их потомство было обречено на гибель.

Рачки, встречающиеся у о. Южная Джорджия выносятся сюда водами моря Уэдделла и течения Западных Ветров. Установить в каждом отдельном случае происхождение рачков пока нет возможности. Их вынос к берегам острова происходит, по-видимому, осенью и зимой.

Так, к северо-востоку от Южных Оркнейских островов в свое время были обнаружены многочисленные «пятна», состоящие из личинок E. superba. Гидрологические данные показывают, что вероятность последующего заноса рачков из этих «пятен» к о. Южная Джорджия зимой велика. В течение осени, зимы и весны, перемещающиеся вместе с течением и концентрирующиеся у острова рачки, заканчивают личиночное развитие, претерпевают метаморфоз и начинают ювенильный этап своего жизненного цикла. И действительно, в районе острова в уловах обнаруживается почти исключительно одна молодь E. superba.

Дифференцировать ареал E. superba в водах течения Восточных Ветров вследствие слабой изученности этого района достаточно затруднительно. Однако раздельное существование рачков разных возрастных групп в этом районе, отраженное в терминах «криль синих китов» и «криль финвалов», бытующих у китобоев, позволяет предполагать известную упорядоченность распределения рачков и их сезонные циклические миграции в этом районе.

Следует отметить, что имеются определенные особенности изменения количественного распределения E. superba в районе моря Скотин и северной части моря Уэдделла, связанные с прохождением рачками жизненного цикла в годы с разными гидрометеорологическими условиями, а также обусловленные разным направлением выноса рачков. Очень существенно, что эти изменения протекают по-разному в разных частях ареала, так как концентрирование рачков здесь может быть обусловлено разными причинами [8].

Воды моря Уэдделла и моря Беллинсгаузена несут через море Скоша, сквозь дугу Скоша скопления E. superba, которые задерживаются в разных местах в силу тех или иных причин. Рачки концентрируются в районе смешения вод моря Уэдделла и течения Западных Ветров, а также в местах завихрений, обусловленных резким изменением рельефа дна над банками, за островами и т.д. [9]. Повышенные концентрации рачков наблюдались у кромки льда. В значительном количестве рачки встречались у о. Южная Джорджия. На остальной части моря Скоша количество их невелико.

Как было показано в ряде исследований, район южной части дуги Скоша является местом размножения $\mathrm{E}$. superba. Здесь наиболее регулярно встречаются именно половозрелые рачки, но иногда попадается и молодь.

В конце прошлого века рачки довольно регулярно встречались у Южных Оркнейских островов. Их скопления находились как у поверхности, так и в толще воды. Также рачки встречались наиболее регулярно в пределах всей южной части островной дуги Скоша. В этот же временной период у Южных Оркнейских островов встречались в большом количестве сальпы, затруднявшие проведение исследований E. superba. Тем не менее рачки также встречались более или менее регулярно.

Изучение и облов рачков легче было проводить к востоку от Южных Оркнейских островов, где сальпы отсутствовали. Однако обитающие здесь рачки, по данным ряда авторов, не связаны непосредственно с циркуляцией вод моря Уэдделла, а, по-видимому, вынесены из зоны антарктической дивергенции. Поэтому, к рассматриваемым скоплениям «уэдделловских» особей эти концентрации отношения не имеют. Лишь некоторое количество рачков, державшихся довольно плотно, но на небольшой акватории, было обнаружено у северного побережья Коронейшн (март-апрель).

Таким образом, в конце XX века каждый год в районе зоны смешения вод моря Уэдделла и течения Западных Ветров концентрировались половозрелые рачки. По-видимому, гидрологические условия в этом районе обеспечивали устойчивость концентраций рачков в период спаривания и нереста. Эта зона была достаточно стабильна от года к году и, по крайней мере, в конце 
лета - начале осени, лишь незначительно меняла свое местоположение. Ее устойчивость и близость к основной зоне ареала (а может быть и принадлежность к ней) и обусловливала регулярность появления здесь рачков, как следствие ежегодного развития популяции Е. superba.

Различие в характере количественного распределения рачков, отмеченное в разные годы, связано с тем, что в одни и те же календарные сроки разных по гидрометеорологическим условиям лет наблюдались разные фазы репродуктивного цикла. С этой точки зрения наиболее подробно изучен район к востоку и северо-востоку от Южных Оркнейских островов.

Вполне очевидно, что в теплые годы биологическая весна наступает раньше, происходит более ранний, чем обычно, нерест, ускоряется последующее рассредоточение рачков. В более холодные годы все эти процессы, естественно, запаздывают.

Таким образом, зависимость частоты встречаемости рачков от их физиологического состояния (стадии репродуктивного цикла) видна совершенно очевидно. Во время нереста рачков в районе зоны смешения можно встретить довольно легко. По мере завершения нерестового периода они попадаются все реже и реже. Давно отнерестившиеся рачки вылавливаются единично.

На остальной части южной половины дуги Скоша наступление одинаковых фаз репродуктивного цикла должно происходить каждый год в те же сроки, что и у Южных Оркнейских островов. Правда ход биологических процессов, о котором судили по фазам репродуктивного цикла, в восточных районах исследованной акватории несколько запаздывает по сравнению с западными.

В районе южной части дуги Скоша в ряде случаев попадалась молодь, выносимая к зоне смешения осенью. Правда, ее было меньше, чем половозрелых рачков в разгар нереста. На вынос молоди оказывает влияние гидрологический режим.

В районе о. Южная Джорджия, являющемся стерильной зоной выселения E. superba, рачки встречаются тем не менее достаточно регулярно. Так же, как и в районе южной части дуги Скоша, скопления рачков здесь нестабильны. Рачки сюда заносятся извне, в районе острова размножения не происходит. Поэтому появление здесь скоплений рачков происходит не в результате размножения местной популяции, а благодаря экспатриации рачков из районов южной части дуги Скоша. Попадая в район острова, рачки концентрируются в его «теневой» зоне. Однако, по данным В.В. Масленникова, задержка в этом районе вынесенных рачков происходит далеко не всегда. Она бывает только при наличии определенной схемы локальных циркуляций в пределах острова [1].

Не случайно, что когда рачки здесь встречались наиболее регулярно и в одном и том же месте, система течений в районе северо-восточного побережья острова была очень сходной. С другой стороны, при неблагоприятных гидрологических условиях рачков у острова обычно меньше или они могут отсутствовать совсем.

Таким образом, задержка рачков, занесенных в район о. Южная Георгия, происходит в силу механических причин и биологической основы, как в районе Южных Оркнейских островов, под собой не имеет. Это, несомненно, должно оказывать определенное влияние на устойчивость нахождения здесь рачков. По-видимому, они могут задерживаться в районе теневой зоны острова до тех пор, пока местные шельфовые течения не претерпят соответствующих изменений.

\section{Выво $\triangle$}

Таким образом, короткий жизненный цикл предполагает существенные изменения частоты встречаемости рачков в одном и том же районе в течение года. Это хорошо видно на примере акватории Южных Оркнейских островов, где половозрелые рачки отмирают по мере завершения репродуктивного цикла. Это приводит к уменьшению количества встречающихся в этом районе особей данного вида. Частота встречаемости молоди E. superba более стабильна, но особи возрастной группы популяции распределены по акватории обычно более равномерно. Молодь текущим летом находится в более или менее неизменном физиологическом состоянии. В результате причины такого характера не могут повлиять на частоту встречаемости молоди в каждом данном районе. Лишь в тех случаях, когда рачки собираются в местах аномалий поля течений, задержка их там длится столько времени, сколько остаются неизменными соответствующие факторы среды.

В районе зоны смешения вод моря Уэдделла и течения Западных Ветров рачки встречаются более регулярно. Их появление и пребывание там зависит от биологических причин и должно наблюдаться каждый год. Вынос нерестовых скоплений в район зоны смешения происходит регулярно каждый год, так как это явление непосредственно связано с жизненным циклом и является одним из существенных его элементов. Что касается района о. Южная Георгия, то, во-первых, сам занос рачков в его воды может благодаря изменениям системы течений в море Скоша не состояться вовсе. Во-вторых, даже заносимые сюда рачки могут в отдельные годы благодаря отсутствию концентрирующих 
факторов встречаться сравнительно редко, распределяясь очень дисперсно. То есть частота встречаемости рачков в отдельных местах этого района зависит от чисто случайных, механических причин. То же касается и устойчивости нахождения рачков в этих местах.

Задержка рачков, занесенных в район о. Южная Георгия, происходит в силу механических причин и биологической основы, как в районе Южных Оркнейских островов под собой не имеет. Это, несомненно, должно оказывать определенное влияние на устойчивость нахождения здесь рачков. По-видимому, они могут задерживаться в районе теневой зоны острова до тех пор, пока местные шельфовые течения не претерпят соответствующих изменений.
Следует понимать, что изменения уже происходят в Южном океане, и они будут оказывать влияние на физиологию криля: рост конкуренции среди этих видов, рост популяционных процессов (например, размножение, поведение) криля; рост различных временных промежутков; рост охоты хищников криля и др.

Таким образом, криль является ключевым фактором, определяющим будущее рыболовство, что необходимо учитывать в будущих правилах принятия решений, используемых для управления промыслом криля, а также для всей экосистемы. Для оценки влияния и изменения сезонных или долгосрочных климатических факторов на популяции эвфаузиид необходимо проводить мониторинг размера запаса и распределения криля.

\section{ЛИТЕРАТУРА}

1. Агеев А.В. Предпосылки отечественного промысла антарктического криля. // Рыбное хозяйство. 2015. № 6. С. 61-65.

2. Жук Н.Н., Корзун Ю.В. Размерный состав антарктического криля Euphausia superba и гидрометеорологические факторы в проливе Брансфилд В сезоны 2014-2017 гг. // Вестник Керченского государственного морского технологического университета, 2018. Выпуск № 1.2018. С. 28-38.

3. Временное распределение порогового уровня на промысле Euphausia superba в статистических подрайонах 48.1, 48.2, 48.3 и 48.4. CCAMLR-XXXV/30. 2016. 6 c.

4. асаткина С.М., Петров А.Ф., Шуст К.В., Урюпова Е.Ф., Сытов А.М. Характеристика современного промысла антарктического криля Euphausia superba (период с 2003 по 2013 г.) в Антарктической части Атлантики (АчА) // Рыбное хозяйство. 2014. № 5. С. 69-74.

5. ARK www.ark-krill.org/. Accessed Feb 2015

6. Backes J.M., Howard P.A. Krill oil for cardiovascular risk prevention: is it for real? Hosp Pharm 49(10):907-912. 2014.

7. Hill S.L., Atkinson A., Darby C., Fielding S., Krafft B.A.,. Godo 0.R, Skaret G., Trathan P.N., Watkins J.L. Is current management of the Antarctic krill fishery in the Atlantic sector of the Southern Ocean precautionary? CCAMLR Science. 2016. 23: 31-51.

8. FAO Fisheries and Aquaculture Department. FishStatJ — Software for fishery and aquaculture statistical time series. URL: http://www.fao.org/fishery/ statistics/software/fishstatj/en (дата обращения: 18.01.2021).

9. Fishery monitoring catch report. KRI481_20181116. Hobart:CCAMLR, 2018. 3 p.

10. Marr J.W.S. The natural history and geography of the antarctic krill (Euphausia superba Dana) Discovery Reports, XXXII, 1962.

11. Nicol S, Foster J, Kawaguchi S. The fishery for Antarctic krill — recent developments. Fish. 2012. 13(1):30-40 